\title{
Modeling ANd Simulation Of A Clustered WSN For PRECISION AgRICULTURE
}

\author{
Divya Mishra, Deepak Sethi and Partha Pratim Bhattacharya \\ College of Engineering and Technology, Mody University of Science \& Technology, \\ Lakshmangarh, Rajasthan, India- 332311
}

\begin{abstract}
Hundreds or thousands of sensor nodes are deployed in WSN to sense the environment and are application specific. Sensor node's responsibility is to sense the environment and send the report to the head node (sink). Various methods of data reporting in WSN are query driven, time driven, event driven or hybrid. Routing protocols are classified into three main categories such as: flat routing, hierarchical routing and location based routing. These routing protocols can use single or multi-hop data reporting methods for transmission of data to neighbor nodes or to base station. In this paper, we have surveyed and compared various hierarchical routing protocols for application in agricultural field such as LEACH, LEACH -C, TEEN, SEP and DEEC based on the parameters like energy efficiency, heterogeneity level, cluster stability, cluster head selection criteria etc.
\end{abstract}

\section{INTRODUCTION}

WSN is basically a network which consists of several wireless sensor nodes with limited battery power and a destination head node also called as sink node. Sensors are simply small devices that are designed in such a way that they are capable to monitor the surrounding about certain changes and respond immediately to the head node (sink). Sensor nodes consume their limited energy to perform functions like collecting, processing and aggregating the data and pass it to sink node then user can access the data through the internet as shown in figure 1 [1-4].

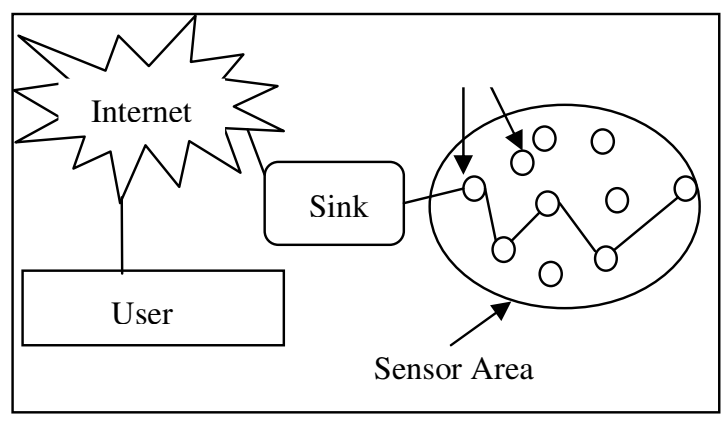

Fig.1 Architecture of WSNs

The WSN is used in various fields of everyday life activities or services like monitoring and controlling traffic, weather areas, structural health monitoring, agriculture, healthcare and medical research, homeland security, military applications, monitor environmental pollutant detection of chemical/biological agents, fire detection in forest [5].

DOI : $10.5121 /$ ijcsitce.2016.3203 


\section{Applications Of WSN In Agriculture}

The science of developing most innovative and advanced technology in order to enhance the crop production is known as precision agriculture. Wireless sensor network plays an important role for developing these advanced technologies for precision agriculture and replace old ordinary techniques. It is very necessary for farmers to monitor and control the equal distribution of rain water to all crops in the whole farm because sometime rain water is unequal distribution to the crops that affect progress of crop. Wireless sensor network of agriculture field comprises no of sensor nodes which have their own different sensing duty like soil wetness sensing, leaf moisture sensing, soil pH sensing etc. and a server node (sink) and all nodes are wirelessly connected with each other. When sensed data received by the sink node from sensor nodes then sink node has responsibility to perform action against the received value. If sensed data show water deficiency then sink node enables the water sprinkle activity to fulfill water requirement of crops. After satisfying water need of crops, the water sprinkler is automatically switched off so simply water can be conserved by using wireless technology. Similarly when the value of soil $\mathrm{pH}$ sensor is sent to the sink node then sink node should inform the farmer about the soil $\mathrm{pH}$ level by sending message over the farmer's phone. By using this information, for the next crop season farmer can selects necessary fertilizer and he can reduce the amount of fertilizer. Thus automated control of water sprinkling and ultimate supply of information to farmers is done as a result of this project using wireless sensor network [6].

\section{CLUSTERED ROUTING IN WSN}

\section{A.LEACH Protocol}

Low Energy Adaptive Cluster Hierarchy (LEACH) [7] based protocol is first hierarchical clustering energy efficient routing protocol that reduces the energy consumption of node by cluster formation so it directly increases network life. In LEACH, clusters are formed by dividing the network into small manageable no of units. And each cluster has a particular node called Cluster head $(\mathrm{CH})$ that has the responsibility to send the aggregated data from all nodes to the sink node. $\mathrm{CH}$ is selected randomly so that the energy dissipation among nodes can be balanced [7]. LEACH Algorithm contains a periodic process in which each round has two phases-

\section{1)Setup phase}

a) Advertisement Phase: In this phase, the $\mathrm{CHs}$ send advertisement packet to their neighborhood. By this packet, nodes get to know to which $\mathrm{CH}$ they are belonging. Every node $\mathrm{n}$ in the network chooses a random number $k$ between 0 and 1 . If $k<T(n)$ for node $n$, the node becomes a clusterhead. The selection of cluster heads will be done by the following equation (1):

$$
T(n)=\left\{\begin{array}{lc}
\frac{P}{1-P\left[r * \bmod \left(\frac{1}{P}\right)\right]} & \text { ifn } \epsilon G \\
0 & \text { Otherwise }
\end{array}\right\}
$$

Where $P=$ the desired percentage of cluster heads 
(e.g., $P=0.05$ ), $r=$ the current round, and $G$ is the set

of nodes that have not been cluster-heads in the last

$1 / P$ rounds [7].

B)Cluster Set-up Phase: $\mathrm{CH}$ received information about its member nodes.

c) Schedule Creation: $\mathrm{CHs}$ provide a time schedule for each node in which they can send their data to respective $\mathrm{CH}$.

\section{1)Steady-State phase}

Data Transmission: In first transmission all nodes transmit their data to respective $\mathrm{CH}$. In second transmission once $\mathrm{CH}$ received all data from its members it minimize the data without losing meaning of data so that it can save energy instead of sending the complete data. And then send minimized data to destination node (sink).

Although LEACH protocol reduces the transmission energy and does not require global knowledge of network but still it have problems like:

- CHs are randomly selected, so network cannot remain with uniform energy dissipation.

- Because LEACH uses single hop transmission so it is not able to cover a wide area.

\section{C.LEACH-C protocol}

The only difference between LEACH protocol and LEACH-C protocol is in their Setup phase however the Steady state phase remains ideal in both of them. In LEACH-C cluster formation is performed by the base station (sink), unlike LEACH where nodes self-elect themselves as $\mathrm{CH}$. Initially in the LEACH-C, all nodes of the network send their information like: location, energy level to the Base Station (BS) [8]. After this BS calculates optimal number for nodes can be CH. Only those nodes can be $\mathrm{CH}$ who has sufficient energy. Advantages of this protocol over LEACH are number of $\mathrm{CH}$ in LEACH are not fixed it changes according to round to round but in LEACH-C BS calculates number of $\mathrm{CH}$ for every round.

Drawback of LEACH-C is sink node require global knowledge of network for cluster formation.

\section{D.TEEN Protocol}

Threshold sensitive Energy Efficient sensor Network protocol (TEEN) [9] is also a cluster-based hierarchical routing protocol like LEACH i.e. the nodes form clusters and selection of $\mathrm{CH}$ for transmission of data to BS. It uses both hierarchical technique and data-centric approach. Transmission of data is done less frequently so it saves energy efficiently. It is reactive protocol in which nodes are sensitive to certain activities like temperature weather etc. so reactive protocols are best suited for time critical activities. While inside LEACH, absolutely no certain action are generally driven therefore it is a proactive protocol. The actual nodes behave instantly for immediate and also for extreme changes in the value of a sensed attribute. A pair of Thresholds is employed to check sensing changes: 
(1) Hard threshold: This threshold value is assigned by the $\mathrm{CH}$ to the sensed attribute. When sensor node's sensed value is larger than the hard threshold value then this is the sign for nodes to switching on its transmitter and inform to its $\mathrm{CH}$.

(2) Soft threshold: This is the value of the sensed attribute if this value has some small change then it imply the node to switch on its transmitter and transmit.

So data transmission happen only in two conditions either the sensed data value is larger than the hard threshold value or changes in the value of sensed attribute is greater than/ equal to the soft threshold value.

\section{E.SEP Protocol}

A network which consist number of nodes with same level of energy means all sensor nodes are equipped with significantly equal amount of energy then such networks are known as Homogeneous sensor network. Discussed routing schemes LEACH, LEACH C, TEEN are advisable only for homogenous sensor network. So for heterogeneous purpose in terms of energy, Stable election protocol (SEP) [10] was proposed which carried two level heterogeneity for sensor network. Here two-level heterogeneous sensor network means out of the total population of sensor nodes, some nodes are having significant more battery power (energy) then the remaining nodes in the sensor network. Nodes which are having more energy power are known as advanced nodes. Suppose sensor network composed of total N number of sensor nodes and each node is equipped with $\mathrm{E}_{0}$ initial energy. For heterogeneity, let $\mathrm{M} \times \mathrm{N}$ be the number of advanced nodes where $\mathrm{M}$ is a fraction of total number of nodes. Let advanced nodes have A times more energy than rest of nodes. So initial energy of each advanced node in the network is $\operatorname{Eo} \times(1+A)$. Thus total initial energy of two level heterogeneous networks could be represented by equation (2).

$$
\begin{gathered}
\text { Etotal }=N \times(1-M) \times E o+N \times M \times E_{0} \\
\text { Etotal }=E o \times(1+A \times M)
\end{gathered}
$$

For a node to become a $\mathrm{CH}$ it should have optimal probability $\mathrm{P}_{\mathrm{opt}}$, defined as in equation (3):

$$
\text { Popt }=\frac{K_{o p t}}{N}
$$

Here $\mathrm{k}_{\mathrm{opt}}$ is optimal number of constructed clusters. When distance of a population of nodes to the sink is less than $\mathrm{d}_{\mathrm{o}}$ where $d o=\sqrt{\frac{e_{f s}}{e_{m p}}}$, then value of kopt given by the equation (4):

$$
K_{\text {opt }}=\sqrt{\frac{N}{2 \pi}} \frac{X}{D}
$$

When distance of a population of nodes to the sink is more than $d_{0}$ then value of kopt defined by equation (5):

$$
K_{o p t}=\sqrt{\frac{N}{2 \pi}} \sqrt{\frac{e_{f s}}{e_{m p}}} \frac{X}{D^{2}}
$$

Let area of network $=\mathrm{X} \times \mathrm{X}, \mathrm{D}=$ Average distance from a $\mathrm{CH}$ to the sink node, $\mathrm{N}=$ no of nodes in network. $e_{f s}$ and $e_{m p}$ depend on the transmitter amplifier model [9]. For every round, the average 
number of constructed $\mathrm{CH}$ should be $\mathrm{N} \times$ Popt and its fix (constant) to minimize the energy consumption of nodes. SEP protocol assigns a weight to the optimal election probability (Popt) to maintain the fix number of $\mathrm{CH}$ per round. Thus weighed election probabilities for normal and advanced nodes are shown by equations (6) and (7) respectively:

$$
\begin{aligned}
\text { Pnrm } & =\frac{\text { Popt }}{1+A \cdot M} \\
\text { Padv } & =\frac{\text { Popt }}{1+\mathrm{A} \cdot \mathrm{M}} \times(1+A)
\end{aligned}
$$

As election probabilities are changed so the threshold value for normal and advanced nodes can be defined by equation (8) and (9) respectively:

$$
\begin{aligned}
& T(\text { snrm })=\left\{\begin{array}{ll}
\frac{\text { Pnrm }}{1-\text { Pnrm. }\left(\operatorname{rmod} \frac{1}{\text { Pnrm }}\right)} & \text { if snrm } G^{\prime} \\
0 & \text { if snrm } G^{\prime}
\end{array}\right\} \\
& T(\operatorname{sad} v)=\left\{\begin{array}{ll}
\frac{P a d v}{1-P a d v \cdot\left(\operatorname{rmod} \frac{1}{\text { Padv }}\right)} & \text { if } s a d v \in G^{\prime \prime} \\
0 & \text { ifsadv } \in G^{\prime \prime}
\end{array}\right\}
\end{aligned}
$$

Where, $r$ is the current round, $\mathrm{G}^{\prime}$ is the set of normal nodes that have not become $\mathrm{CHs}$ within the last 1/Pnrm rounds of the epoch and $G$ " is the set of advanced nodes that have not become cluster heads within the last 1/Padv rounds of the epoch [10]. Finally, excellence of SEP protocol is that it does not required any global knowledge of nodes in the network for data routing. But SEP cannot perform well for more than two-level heterogeneity in terms of energy of sensor node.

\section{F.DEEC Protocol}

In DEEC [11], selection of CHs is not only based on the election probability. In addition DEEC protocol merges a ratio of residual energy of each node and the average energy of network to the election probability. The nodes with high initial and residual energy will have more chances to become the $\mathrm{CH}$ than the other nodes with low energy. In DEEC protocol election probability of each node include residual energy and average energy of network. Let $\bar{E}(r)$ denote the average energy at round $r$ of the network, which defined as in equation (10):

$$
\bar{E}(r)=\frac{\text { total residual energy of all nodes at round } r}{\text { no of nodes }}
$$

For two levels heterogeneous network by adding residual and average energy concept we get election probability formula as in equation (11)

$$
p i=\left\{\begin{array}{c}
\frac{P_{o p t} E_{i}(r)}{(1+A M) \bar{E}(r)} \quad \text { if } s_{i} \text { is the normal node } \\
\frac{P_{o p t}(1+A M) E_{i}(r)}{(1+A M) \bar{E}(r)} \text { if } s_{i} \text { is advanced node }
\end{array}\right\}
$$

As DEEC consider multilevel heterogeneity in terms of node's energy then we get election probability for $\mathrm{CH}$ selection as in equation (12): 
International Journal of Computational Science, Information Technology and Control Engineering (IJCSITCE) Vol.3, No.1/2, April 2016

$$
p i=\frac{P_{o p t} N(1+A) E i(r)}{\left(N+\sum_{i=1}^{N} A_{i}\right) \bar{E}(r)}
$$

Let $\operatorname{Eavg}(\mathrm{r})$ represents the average energy at round $\mathrm{r}$ of the network that is defined in equation in (13):

$$
\operatorname{Eavg}(r)=\frac{1}{N} \operatorname{Etotal}\left(1-\frac{r}{R}\right)
$$

Here R denotes total no round of network which can be calculated by the equation (14):

$$
R=\frac{\text { Etotal }}{\text { Eround }}
$$

Eround is the total energy dissipated in the network during a round, is equal to the equation (15):

Eround $=\quad L\left(2 N\right.$ Eelec $\left.+N E_{D A} k e_{m p} D^{4}{ }_{t o B S} N e_{f S} D^{2}{ }_{t o C H}\right)(15)$

Where, k: number of clusters, L: no of bits in data packet, $E_{D A}$ : data aggregation cost expended in the cluster heads, $D_{t o B S}$ : average distance between the cluster-head and the base station, and $D_{\text {toCH }}$ : average distance between the cluster members and the cluster-head. Eelec: energy dissipated per bit to run the transmitter or the receiver circuit [11].

\section{Simulation And Comparison Of Clustered Routing Protocols}

In agriculture field, different sensors can be used to improve the productivity of crop. There are various types of sensors are available in market like Delta-T Devices, Decagon Devices, The Toro Company etc., are soil moisture sensor to monitor the moisture content in the soil. Digital Soil pH Meter and BEAN, G-Node G301 are types of pH sensor and humidity sensor respectively [12]. In this section, simulation and comparison of various protocols LEACH, TEEN, SEP, DEEC are performed using MATLAB. For this purpose, we use randomly distributed wireless sensor network of 250 nodes in a $500 \mathrm{~m}$ x $500 \mathrm{~m}$ field. We assume the base station is in the center of the sensing region. The radio parameters used in our simulations are shown in Table 1. We will consider following scenarios and examine several performance measures.

Table 1: Network Parameters

\begin{tabular}{|l|l|}
\hline PARAMETERS & Values \\
\hline Area & $500 \mathrm{~m} \times 500 \mathrm{~m}$ \\
\hline No of Nodes & 250 \\
\hline Initial Energy Per Node & $1 \mathrm{~J}$ \\
\hline Total Energy & $250 \mathrm{~J}$ \\
\hline $\begin{array}{l}\text { Transmitting } \\
\text { Energy, ETX }\end{array}$ & $50 \mathrm{~nJ} / \mathrm{bit}$ \\
\hline Receiving Energy, ERX & $50 \mathrm{~nJ} / \mathrm{bit}$ \\
\hline $\begin{array}{l}\text { Data Aggregation } \\
\text { Energy, EDA }\end{array}$ & $5 \mathrm{~nJ} / \mathrm{b} / \mathrm{message}$ \\
\hline $\begin{array}{l}\text { Probability of } \\
\text { Becoming Cluster Head } \\
\text { Per Round }\end{array}$ & 0.1 \\
\hline
\end{tabular}


International Journal of Computational Science, Information Technology and Control Engineering (IJCSITCE) Vol.3, No.1/2, April 2016

\begin{tabular}{|l|l|}
\hline Size of Data Packets & $4000 \mathrm{bits}$ \\
\hline Threshold distance, $\mathrm{d} 0$ & $87.7 \mathrm{~m}$ \\
\hline \multicolumn{2}{|l|}{ Transmit Amplifier Energy } \\
\hline $\begin{array}{l}\text { Energy for Free Space } \\
\text { Loss, EFS }\end{array}$ & $0.0013 \mathrm{pJ} / \mathrm{b} / \mathrm{m}^{4}$ \\
\hline $\begin{array}{l}\text { Energy for Multi-path } \\
\text { Loss, EMP }\end{array}$ & $10 \mathrm{pJb} / \mathrm{m}^{2}$ \\
\hline
\end{tabular}

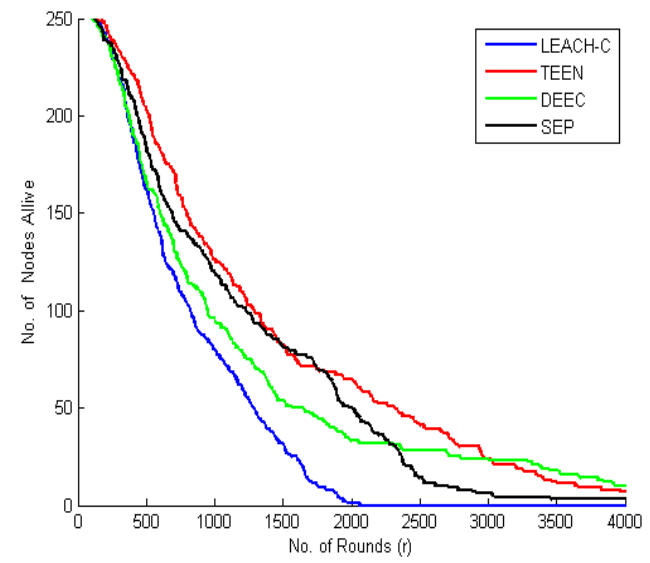

Fig.2: Comparison of LEACH C, TEEN, DEEC, SEP in terms of nodes alive

Figure 2 has shown plot between number of nodes alive and number of rounds of different protocol named as LEACH-C, TEEN, DEEC, SEP which clearly conclude that in large network area like agriculture field where we have to include more number of sensor nodes, TEEN protocol performs well as more number of nodes are remain alive at almost all rounds.

Table 2: comparison of LEACH-C, TEEN, DEEC and SEP in terms of nodes alive

\begin{tabular}{|l|l|l|l|l|}
\hline $\begin{array}{l}\text { No of } \\
\text { Rounds }\end{array}$ & $\begin{array}{l}\text { LEACH- } \\
\text { C }\end{array}$ & TEEN & DEEC & SEP \\
\hline $\mathbf{5 0 0}$ & 162 & 204 & 166 & 184 \\
\hline $\mathbf{1 0 0 0}$ & 80 & 126 & 96 & 120 \\
\hline $\mathbf{2 0 0 0}$ & 1 & 65 & 33 & 50 \\
\hline $\mathbf{3 0 0 0}$ & 0 & 24 & 24 & 6 \\
\hline $\mathbf{4 0 0 0}$ & 0 & 7 & 10 & 3 \\
\hline
\end{tabular}

Table 2 shows the comparison the LEACH- C, TEEN, DEEC and SEP in terms of nodes alive. At 500 rounds, TEEN protocol have 204 sensor nodes are alive whereas rest of the protocols (LEACH-C, DEEC, SEP) have less number of sensor nodes alive $(162,166,184)$. After 2000 rounds, TEEN has more number of nodes alive as compared to other protocols. After 3000 rounds LEACH-C protocol performed worst as all nodes are dead while TEEN and DEEC have equal number of nodes alive. At 4000 round, numbers of alive nodes are zero or fewer in all routing protocols. Therefore, TEEN protocol has more stability in network as compared to other routing protocols. 


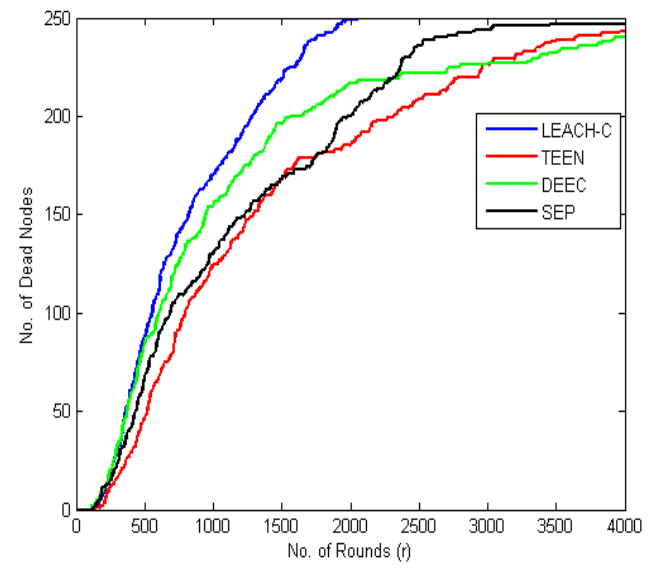

Fig. 3: Comparison of LEACH C, TEEN, DEEC, SEP in terms of nodes dead

Refer Figure 3, it can be observed that TEEN protocol performs better and showed more stability as compared to other protocols while LEACH-C perform worst. The average performance was shown by TEEN and DEEC protocols.

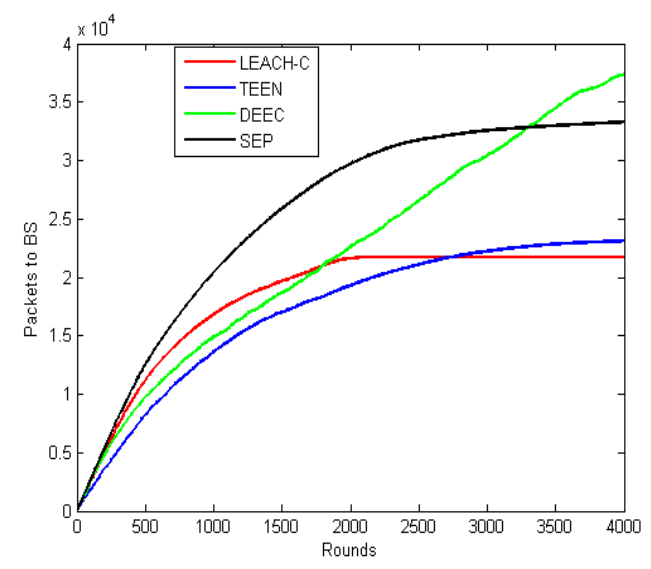

Fig.4: Comparison of LEACH C, TEEN, DEEC, SEP in terms of packets send to BS

Figure 4 showed information about how many data packets send to base station over the number of rounds. In this case, DEEC protocol transfers more data from $\mathrm{CH}$ to base station. So DEEC protocol is more reliable as compared to LEACH-C, SEP and TEEN. Hierarchical routing protocols have their own certain process to choose $\mathrm{CHs}$ and have their unique architecture and many other parameters to perform routing process.

This section does comparison between these protocols based on various parameters like architecture, hop, heterogeneity level, cluster stability etc. as shown in table 3. 
Table 3: Comparison of various routing protocol

\begin{tabular}{|c|c|c|c|c|c|}
\hline $\begin{array}{l}\text { Performance } \\
\text { Criteria }\end{array}$ & LEACH & LEACH-C & TEEN & SEP & DEEC \\
\hline Architecture & Distributed & Centralized & Distributed & Distributed & Distributed \\
\hline Hop & Single Hop & Single Hop & $\begin{array}{l}\text { Multi } \\
\text { Hop }\end{array}$ & $\begin{array}{l}\text { Multi } \\
\text { Hop }\end{array}$ & $\begin{array}{l}\text { Multi } \\
\text { Hop }\end{array}$ \\
\hline $\begin{array}{c}\text { Heterogeneity } \\
\text { level }\end{array}$ & Not present & Not present & Not present & Two level & Multilevel \\
\hline $\begin{array}{l}\text { Cluster Head } \\
\text { Selection } \\
\text { criterion }\end{array}$ & $\begin{array}{c}\text { Elected } \\
\text { rotation- } \\
\text { wise by } \\
\text { probabilistic } \\
\text { approach }\end{array}$ & $\begin{array}{c}\text { Selected by BS } \\
\text { w.r.t. nodes energy } \\
\text { and distance }\end{array}$ & Randomly & $\begin{array}{l}\text { Based on } \\
\text { Initial and } \\
\text { Residual } \\
\text { Energy }\end{array}$ & $\begin{array}{l}\text { Based on Initial } \\
\text { Residual and } \\
\text { Average } \\
\text { Energy of the } \\
\text { network }\end{array}$ \\
\hline Cluster Stability & Lower & Higher than leach & Very High & Moderate & High \\
\hline $\begin{array}{c}\text { Global knowledge } \\
\text { of network }\end{array}$ & $\begin{array}{c}\text { Not } \\
\text { Required }\end{array}$ & Required & Not Required & Not Required & Not Required \\
\hline Energy Efficiency & Very low & Low & Moderate & High & High \\
\hline
\end{tabular}

\section{Conclusion And Future Work}

Cluster formation based routing is the best way to archive energy efficiency goal in hierarchical routing protocols for large area like agriculture field. This paper provides a complete review of some hierarchical routing protocols named as LEACH, LEACH-C, TEEN, SEP and DEEC. The performances of these protocols are judged by the simulation result under the various performance metrics. hence, we can conclude that TEEN is more energy efficient, while DEEC is more reliable because it is sending maximum data packets to base station as compared to other routing protocols. In future, we can propose a concept of mobility in the existing protocols to maximize network lifetime.

\section{REFERENCES}

[1] Siddhi Sharma, Deepak Sethi, P. P. Bhattacharya, "Wireless Sensor Network Structural Design and Protocols: A Survey" Communications on Applied Electronics (CAE) - ISSN : 2394-4714 Foundation of Computer Science FCS, New York, USA Volume 2 - No.1, June 2015 www.caeaccess.org.

[2] Nikolaos A. Pantazis, Stefanos A. Nikolidakis and Dimitrios D. Vergados, Senior Member, IEEE, "Energy-Efficient Routing Protocols in Wireless Sensor Networks: A Survey" IEEE COMMUNICATIONS SURVEYS \& TUTORIALS, VOL. 15, NO. 2, SECOND QUARTER 2013

[3] Siddhi Sharma, Deepak Sethi, P. P. Bhattacharya, "Artificial Neural Network based Cluster Head Selection in Wireless Sensor Network" International Journal of Computer Applications (0975 8887) Volume 119 - No.4, June 2015

[4] Neha Narula, Deepak Sethi, P. P. Bhattacharya "Transmission of Secured Image using DWT-SVD Technique for Applications in Wireless Sensor Network" International Journal of Computer Applications (0975 - 8887) Volume 119 - No.6, June 2015.

[5] Purnima Bholowalia, Arvind Kumar, "Energy Efficient Hierarchical Routing in WSN: A SURVEY", International Journal of Advanced Research in Computer Science and Sof1tware Engineering, Volume 4, Issue 8, August 2014. 
[6] N.Sakthipriya "An Effective Method for Crop Monitoring Using Wireless Sensor Network" MiddleEast Journal of Scientific Research 20 (9):1127-1132, 2014 ISSN 1990-9233 CIDOSI Publications, 2014 DOI: $\quad$ 10.5829/idosi.mejsr.2014.20.09.114152

[7] Wendi Rabiner Heinzelman, Anantha Chandrakasan, and Hari Balakrishnan "Energy-Efficient Communication Protocol for WirelessMicrosensor Networks" Proceedings of the 33rd Hawaii International Conference on System Sciences - 2000.

[8] Wendi B. Heinzelman, Anantha P. Chandrakasan, Hari Balakrishnan, "An Application-Specific Protocol Architecture for Wireless Micro sensor Networks" IEEE TRANSACTIONS ON WIRELESS COMMUNICATIONS, VOL. 1, NO. 4, OCTOBER 2002.

[9] A. Manjeshwar and D. Agrawal, "TEEN: a Routing Protocol for Enhanced Efficiency in Wireless Sensor Networks," International Proc. of the 15th Parallel and Distributed Processing Symposium, PP 2009-2015, 2001.

[10] GEORGIOS SMARAGDAKIS IBRAHIM MATTA AZER BESTAVROS,"SEP: A Stable Election Protocol for clustered heterogeneous wireless sensor networks" Second International Workshop on Sensor and Actor Network Protocols and Applications (SANPA2004), 2004.

[11] L. Qing, Q. Zhu, M. Wang, "Design of a distributed energy-efficient clustering algorithm for heterogeneous wireless sensor networks".ELSEVIER,Computer Communications 29, pp2230-2237, 2006.

[12] Aurelio Cano1,2, José Luís Añón1, Candid Reig1*, Cristina Millán-Scheiding3, Ernesto LópezBaeza2 "Automated Soil Moisture Monitoring Wireless Sensor Network for Long-Term Cal/Val Applications", Wireless Sensor Network, 2012, 4, 202-209.http://dx.doi.org/10.4236/wsn.2012.48030 Published Online August 2012 (http://www.SciRP.org/journal/wsn). 